\title{
The effect of Ivermectin pour-on administration against natural Nematodirus spathiger infestations and prevalent rate of that in cattle
}

\author{
Khayatnouri Mirhadi $^{1 *}$, Garedaghi Yagoob ${ }^{2}$ and Safarmashaei Saeid ${ }^{3}$ \\ ${ }^{1}$ Department of Pharmacology, Tabriz Branch, Islamic Azad University, Tabriz, Iran. \\ ${ }^{2}$ Department of Parasitology, Tabriz Branch, Islamic Azad University, Tabriz, Iran. \\ ${ }^{3}$ Young Researchers Club, Tabriz Branch, Islamic Azad University, Tabriz, Iran. \\ Accepted 30 May, 2011
}

\begin{abstract}
These days one of the real problems that cause the prejudice-economy in animal farms yearly is parasitic disease. For that reason and to prevent these problems the use of antiparasitic drugs is necessary. Ivermectin is a broad spectrum antiparasitic agent and is in different dosage forms such as injection, oral and pour-on. The aims of this study was to evaluate the efficacy of ivermectin pour-on administration against natural Nematodirus spathiger nematode infections in cattle and also to determine the prevalent rate of this parasite in Tabriz area. In this study, 120 heads of male and female hybrid cattle were used for LPG (larves per gram of feces) feces test. Willis method was applied for feces test and Stoll method was used for counting nematode larvae (LPG). After confirming worm contamination and counting $N$. spathiger nematode larves in feces in infected animals, ivermectin (0.5 $\mathrm{mg} / \mathrm{kg}$ ) pour-on was administrated. Feces test was repeated in 1, 7, 21 and 28 days after treatment. Results showed that total prevalence of $\boldsymbol{N}$. spathiger nematode infections was $33.33 \%$ in cattle of Tabriz area. The effects of ivermectin pour-on on $N$. spathiger nematode were $13.37,44.96,83.69$ and $99.1 \%$ in $1,7,21$ and 28 days respectively. In conclusion, because the effect of this drug against $N$. spathiger nematode was $>99 \%(p<0.05)$, cattle can use this drug in anti-parasitic programme. Of course, the effect of this drug on other nematodes and parasitic infections need more investigation.
\end{abstract}

Key words: Ivermectin, pouron administration, Nematodirus spathiger, cattle.

\section{INTRODUCTION}

Infestations with gastrointestinal (Gl) nematodes are very common on cattle farms in Iran and all over the world. Parasitic infections of cattle are major factors responsible for economic losses through reduction in productivity and increased mortality. Parasites cause the animals to be unthrifty which may include the loss of weight, low birth weights and difficulty in kidding. Due to parasitism, the animals become susceptible to other health problems which can lead to death. However, there is substantial

*Corresponding author. E-mail: khayat_nouri@yahoo.com, mh.khayatnouri@iaut.ac.ir Tel: 00989143005855 evidence that they can also exert important negative effects on the productivity of adult dairy cows (Sanchez et al., 2004a). Many researches on prevalent rate of gastrointestinal parasites all over the world have been done but research on the effect of anti parasitic drug by different administrations is low, and in Iran the study on the present subject has not been done (Gayrard et al., 1999; Hooke et al., 1997; Georgi and Georgi, 1990; Kassai, 1999; Reinemeyer and Courtney, 2001; Soulsby, 1986; Urquhart et al., 2003). Ivermectin is a member of the macrocyclic lactone class of endectocides, commonly referred to as avermectins.

It is labeled for the treatment of internal and external parasites in dogs, cats, horses, pigs, sheep, and cattle. 
Table 1. Average number of enumerating the larvae in fecal samples of different days of before and after the treatment with pour on Ivermectin.

\begin{tabular}{ccccc}
\hline Before treatment & 1 Day after treatment & 7 Days after treatment & 21 Days after treatment & 28 Days after treatment \\
\hline 785 & 680 & 432 & 128 & 7 \\
\hline
\end{tabular}

Table 2. Rate of Ivermectin pour on administration effect in different days after treatment for control of Nematodirus spathiger.

\begin{tabular}{cccc}
\hline 1 Day after treatment & 7 Days after treatment & 21 Days after treatment & 28 Days after treatment \\
\hline 13.37 & 44.96 & 83.69 & 99.1 \\
\hline
\end{tabular}

Subcutaneous (SC) and topical (TOP) formulations are available for use in nonlactating dairy cattle, at a dose of 0.2 and $0.5 \mathrm{mg} / \mathrm{kg}$ body weight (BW), respectively. Ivermectin is a highly potent broad-spectrum anthelmintic that is widely used in cattle. It is available in injectable, oral and topical formulations for use in cattle (Chaudhri et al., 2003; Vermunt et al., 1995). The most important Gl nematode, responsible for considerable production losses in cattle is Nematodirus spathiger (Armour, 1989; Mandal, 2006). Study on pour on administration of ivermectin on $N$. spathiger and the facile use of this drug have not been done in Iran. The objective of this paper is to determine the evaluation of the effect of ivermectin pour-on administration against natural $N$. spathiger nematode infections and their prevalent rate in cattle. This study is the first report in Iran.

\section{MATERIALS AND METHODS}

In the present study, a total number of 120 dubious cattle with $N$. spathiger infestation, from 20 different farms in Tabriz area were collected for fecal examination and LPG. After 3 times fecal examination, a total number of 200 cattle infected with $N$. spathiger were distinguished and after this step, infected cattle were isolated and then pour on Ivermectin at a dose of $0 / 5 \mathrm{mg} / \mathrm{kg}$ was administrated. Also, pour on form of Ivermectin done by melting the Ivermectin powder in solution of Isopropyl alcohol (weight-weight) with $0.5 \%$ concentration was made (Reinemeyer and Courtney, 2001). In this study differential diagnosis of $N$. spathiger larvae from other larvae of authentic book was used (Urquhart et al., 2003), also exact distinguishing of fecal culture and shape of $\mathrm{L}_{3}$ (stage form of larvae) was used (Urquhart et al., 2003). Before and after the beginning of cattle treatment, 3 times fecal samples were taken for fecal examination and after examination, results of larvae enumeration in one designed form was written. Fecal examination in days of 1, 7, 21 and 28 after treatment was repeated. In this study, Willis method was used for fecal examination and Stool method was used for larvae examination (LPG) (Georgi and Georgi, 1990; Kassai, 1999; Soulsby, 1986; Urquhart et al., 2003). At the end, the following formols were used to determine the effective rate of pour on administration of Ivermectin:

$\%$ of drug efficacy $=\mathrm{P}-\mathrm{R} / \mathrm{P} \times 100$

$\mathrm{R}=$ Average of parasite larvae number in gram of fecal sample after treatment.
$\mathrm{P}=$ Average of parasite larvae number in gram of fecal sample before treatment (Rehbein et al., 1999).

Data were analyzed by non-parametric crosscal-walis and $p<0.05$ was considered significant (Aguirre et al., 2005; Marley et al., 1995).

\section{RESULTS}

Of the 120 cattle used in this study, 40 heads of them infected with $N$. spathiger were distinguished and the prevalent rate $(33.33 \%)$ of this parasite was calculated. Average number of enumerated larvae was 785 . The average number of enumerated larvae in fecal samples of different days after treatment with pour on Ivermectin is shown in Table 1. The rate $(13.37,44.96,83.69$ and 99.1) is shown in Table 2 the Ivermectin pour on administration effect in different days after treating with formol was calculated in days $1,7,14$ and 21 , respectively. The ivermectin pour on administration reduced the natural parasite infestation.

\section{Conclusion}

According to results of Crosscal-walis test, we can say which pour on administration of Ivermectin cases decreases the natural infestation of cattle with $N$. spathiger. The efficacy rate of Ivermectin on this parasite is higher than $99 \%$. These days Ivermectin has different drug shapes. Half of intra venal administration of Ivermectin with dose of $300 \mu \mathrm{g} / \mathrm{kg}$ in cattle is 2.8 day, but subcutaneous administration with dose of $200 \mu \mathrm{g} / \mathrm{kg}$ is 8 day. It is also shown that the effect of sustain-released administration of this drug in cattle is more than that of oral and subcutaneous administration (Rehbein et al., 1999). The importance of using anti-parasitic drug is the increase of contact time of drugs, which is very effective compared to increase in the dose of these drugs (Georgi and Georgi, 1990; Kassai, 1999; Reinemeyer and Courtney, 2001; Soulsby, 1986; Urquhart et al., 2003). This subject has demonstrated that Ivermectin with dose of $1 \mathrm{mg} / \mathrm{kg}$ (oral or injection) has effective anti-parasitic 
role in veterinary. The dose of this drug in cattle for oral and subcutaneous administration is $0.2 \mathrm{mg} / \mathrm{kg}$ and for pour on administration is $0.5 \mathrm{mg} / \mathrm{kg}$; these doses of Ivermectin have important antihelmintic effect between 97 to $100 \%$ on adult form and $L_{4}$ (forth stage of larvae) of Haemonchus, Ostertagia, Cooperia, Trichostrongylus, Strongyloides, Bonostomum, Nematodirus, Trichuris, Oesophagostomum, Dictyocaulus and Chabertia ovina. Also, these doses have effective role in reducing some arthropods (Georgi and Georgi, 1990; Kassai, 1999; Reinemeyer and Courtney, 2001; Soulsby, 1986; Urquhart et al., 2003). According to findings of researchers tablet form of Ivermectin with dose of 0.4 $\mathrm{mg} / \mathrm{kg}$ reduces eggs in feces during 10 week after treatment, but have no protective role for reinfection of cattle with one dose of drug administration. Subcutaneous administration of Ivermectin with dose of $0.2 \mathrm{mg} / \mathrm{kg}$ and pour on of that with $0.5 \mathrm{mg} / \mathrm{kg}$ dose have high effective role in controlling parasites, and protective role for reinfection in cattle.

Also, according to findings of researchers one administration of Ivermectin with dose of $0.5 \mathrm{mg} / \mathrm{kg}$ has highly effective between 95 to $100 \%$ on Haemonchus, Oesophagostomum and Bunostomum (Egerton et al., 1981; Gary and Kumar, 2007; Reinemeyer and Courtney, 2001); and when Ivermectin with present dose was used, it had effect on Boophilus, Damalina and other arthropods (Borges et al., 2008; Barth and Preston, 1988; Colwell and Jacobsen, 2002; Lonneux et al., 1997; Kassai, 1999; Marley et al., 1993; Reinemeyer and Courtney, 2001). Doramectin (99.2 and 90.7\%) were administered (with Ivermectin in one family) after 14 and 21 days, respectively on Cooperia; 99.9 and $93.7 \%$ on Ostertagia, after 21 and 28 days, respectively; 100 and $99.9 \%$ on Dictyocaulus has important effect. In one study on natural infestation of cattle, Doramectin deleted this infestation of Ostertagia and Cooperia, respectively in days 19 and 22 .

The effect of drug on most parasites is after 14 days; therefore permanent drug on the surface of the body is very important (Williams et al., 1997). In the present study, effective rate $(99.1 \%)$ was in day 28 after treating with pour on Ivermectin administration on $N$. spathiger, confirming that of Williams et al. (1997) and Williams and Loyacano (1997). Williams et al. (1997), in one study on natural infected cattle with Ostertagia, Cooperia, Oesophagostomum, Trichostrongylus, Haemonchus and Bunostomum compared to the effect of injection of Doramectin and pour on Ivermectin, show which of these 3 drugs decrease the number of eggs and larvae of these parasites in feces; and compared the aspect of these drugs not considered different. They reported which pore on administration of these is similar to injection administration (Williams et al., 1999). Eysker et al. (1998) indicated which of these drugs have protective effect on cattle and reduce the specific antigen of Cooperia oncophora (Eysker et al., 1998). In another study, Williams et al. (1997) compared the effect of pour on administration of Ivermectin, Doramectin, Eprinomectin and Moxidectin. It was shown that Eprinomectin and Ivermectin have maximum and minimum effect (Williams et al., 1997). In one study on comparing the effect of suspension Albendazole, Oxfendazole, and Fenbendazole with pour on Ivermectin on gastrointestinal and respiratory nematods, it was indicated that maximum effect was with pour on administration of Ivermectin with 99.2, 98.3 and $98.1 \%$ effect on Ostertagia, Cooperia and Dictyocaulus respectively and minimum rate was with Fenbendazole (63.6, 17.7 and 39.7\%) and Oxfendazole (78.5, 42.1 and 32\%) (Williams and Loyacano, 1997). Gayrard et al. (1999) say that we can use Ivermectin and Doramectin for control of gastrointestinal parasites in cattle (Gary and Kumar, 2007). Whang et al. (1994) reported that pour on and injection administration of Moxidectin have more positive effect than $90 \%$ on Ostertagia and Cooperia and significant difference between these two types of administration was not reported (Whang et al., 1994). Two studies by Williams et al. (1996) indicated that Moxidectin is very important in controlling parasitic disease (Williams et al., 1996; Williams and DeRosa, 2003).

Skogerboe et al. (1999) reported that pour on administration of Ivermectin during rain has more than $99 \%$ antiparasitic effect; and rain has no specific effect on reducing the role of Ivermectin (Rehbein et al., 1999; Skogerboe et al., 1999). Of course other studies on this subject have been done and indicated that during rain, pour on Ivermectin is active against parasites (Rehbein et al., 1999; Rolfe and Dawson, 1997; Skogerboe et al., 1999). In fact, pour on administration of Ivermectin is very easy for farmers and so far for Ivermectin administration, no specific side effect has been reported (Rehbein et al., 1999; Rolfe and Dawson, 1997; Skogerboe et al., 1999). At the end, we can say Ivermectin is a very effective drug for controlling gastrointestinal parasites in ruminant and its use is very easy, with no need of specific tools. Of course, the effect of pour on administration of Ivermectin on other helminths and arthropods needs more studies.

\section{REFERENCES}

Armour J ( 1989). The influence of host immunity on the epidemiology of trichostrongyle infections in cattle. Vet. Parasitol. 32: 5-19.

Aguirre DH, Gaido AB, Cafrune MM, Castelli ME, Mangold AJ, Guglielmone AA (2005). Eprinomectin pour-on for control of Boophilus microplus (Canestrini) ticks (Acari: Ixodidae) on cattle. Vet. Parasitol., 127: 157-163.

Barth D, Preston JM (1988) Efficacy of topically administered ivermectin against chorioptic and sarcoptic mange of cattle. Vet. Rec., 123: 101104.

Borges FA, Silva HC, Buzzulini C, Soares VE, Santos E, Oliveira GP, Costa AJ (2008). Endectocide activity of a new long-action formulation containing $2.25 \%$ ivermectin $+1.25 \%$ abamectin in cattle. Vet. Parasitol., 155(3-4): 299-307.

Chaudhri SS, Gupta SK, Banerjee DP, Bhatnagar PK, Ruprah NS (2003) Manual of veterinary helminthology. First edition, IBDC (International Book Distributing Company), p. 83. 
Colwell DD, Jacobsen JA (2002) Persistence activity of topical ivermectin against artificial infestation with hypodermal lineatum (Diptera: Ostridae). Vet. Parasitol., 105: 247-256.

Egerton J, Eary C, Suhayda D (1981) The anthelmintic efficacy of ivermectin in experimental infected cattle. Vet. Parasitol., 8: 59-70.

Eysker M, Boersema JH, Githiori JB, Kooyman FNJ (1998). Evaluation of the effect of ivermectin administered topically at zero and six weeks after turnout on gastrointestinal nematode infection in firstseason grazing cattle. Vet. Parasitol., 78(4): 277-286.

Gary R, Kumar RR (2007). Duration of anthelmintic effect of three formulations of Ivermection (oral, injectable and pour-on) against multiple anthelmintic-resistant haemonchuscontortus in sheep. Vet. Res. Commun., S0165-7380.

Gayrard V, Alvinerie M, Toutain PL (1999). Comparison of pharmacokinetic profiles of doramectin and ivermectin pour-on formulations in cattle. Vet. Parasitol., 81(1): 47-55.

Georgi JR, Georgi ME (1990). Parasitology for veterinarians. Fifth edition, WB Saunders Company, pp. 3-5, 152-154, 243-265, 267309.

Hooke FG, Clement P, Dell'Osa D, Porter RM, MacColl D, Rew RS (1997). Therapeutic and protective efficacy of doramectin injectable against gastrointestinal nematodes in cattle in New Zealand: A comparison with moxidectin and invermectin pour-on formulations. Vet. Parasitol., 72(1): 43-51.

Kassai T (1999). Veterinary helminthology. First edition, BH (Butterworth Heinemann), pp. 13-19, 75-83, 147-153, 181-193, 205221.

Lonneux JF, Nguyen TQ, Losson BJ (1997). Efficacy of pour-on and injectable formulations of moxidectin and ivermectin in cattle naturally infected with Psoroptesovis: parasitological, clinical and serological data. Vet. Parasitol, 69(3-4): 319-330.

Mandal SC (2006). Veterinary parasitology at a glance. First edition, IBDC (International Book Distributing Company), pp. 1-61, 203.

Marley SE, Knapp SE, Rognlie MC, Thompson JR, Stoppa TM (1995). Efficacy of ivermectin pour-on against Oestertagiaoestertagi infection and residues in the American Bison, Bison Bison. J. Wildlife Dis., 31(1): 62-65.

Marley SE, Hall RD, Corwin RM (1993). Ivermectin cattle pour-on: duration of a single late spring treatment against horn flies, Haematobiairritans (L.) (Diptera: Muscidae) in Missouri, USA. Vet. Parasitol., 51(1-2): 167-172.

Rehbein S, Barrick RA, Batty AF, Drag MD, Rolfe PF, Cox JL (1999). Evaluation of the effect of simulated rainfall on the ef®cacy of Ivomec Pour-on against Cooperia spp. infection in cattle. Parasitol. Res., 85: 783-786.

Reinemeyer CR, Courtney CH (2001). Antinematodal drugs, Section 11, Chemotherapy of parasitic diseases, In: Adams, HR, Veterinary pharmacology and therapeutics, $8^{\text {th }}$ edition. IowaState University Press/Ames, pp. 963-971.

Rolfe PF, Dawson KL (1997). Efficacy of topical ivermectin following exposure of treated cattle to rains. Vet. Rec., 141: 269-270.

Sanchez J, Dohoo I, Carrier J, DesCoteaux L (2004a). A meta-analysis of the milk-production response after anthelmintic treatment in naturally infected adult dairy cows. Prev. Vet. Med., 63: 237-256.
Skogerboe TL, Cracknell VC, Walstrom DJ, Ritzhaupt L, Karle VK (1999). The effect of simulated rainfall on the efficacy of doramectin pour-on against nematode parasites of cattle. Vet. Parasitol., 86(4): 229-234.

Soulsby EJL (1986). Helminths, arthropods and protozoa of domesticated animals. seventh edition, BailliereTindall, London, pp. 1-4, 228-231, 247-252, 761-777.

Urquhart GM, Armour J, Duncan JL, Dunn AM, Jennings FW (2003). Veterinary parasitology, Second edition, Book Power, Blackwell Science, pp. 31-34, 268-269, 276-279.

Vermunt JJ, West DM, Pomroy W (1995). Multiple resistance to ivermectin and oxfendazole in Cooperia species of cattle in New Zealand. Vet. Record, 137: 43-45.

Whang EM, Bauer C, Kollmann D, Bürger HJ (1994). Efficacy of two formulations ('injectable' and 'pour on') of moxidectin against gastrointestinal nematode infections in grazing cattle. Vet. Parasitol., 51(3-4): 271-281.

Williams JC, Broussard SD, Wang GT (1996). Efficacy of moxidectin pour-on against gastrointestinal nematodes and Dictyocaulus viviparus in cattle. Vet. Parasitol., 64(4): 277-283.

Williams JC, DeRosa A (2003). Dose confirmation of moxidectin $0.5 \%$ pour-on against adults and fourth-stage larvae of various Cooperia spp. and Trichostrongylus colubriformis in Louisiana. Vet. Parasitol., 114(4): 295-303.

Williams JC, DeRosa A, Nakamura Y, Loyacano AF (1997). Comparative efficacy of ivermectin pour-on, albendazole, oxfendazole and fenbendazole against Ostertagia ostertagi inhibited larvae, other gastrointestinal nematodes and lungworm of cattle. Vet. Parasitol., 73(1-2): 73-82.

Williams JC, Loyacano AF (1997). Comparison of the efficacy of two treatments of doramectin injectable, Ivermectin injectable and ivermectin pour-on against naturally acquired gastrointestinal nematode infections of cattle during winter-spring grazing season. Vet. Parasitol., 72: 69-77.

Williams JC, Loyacano AF, DeRosa A, Gurie J, Clymer BC, Guerino F (1999). A comparison of persistent anthelmintic efficacy of topical formulations of doramectin, ivermectin, eprinomectin and moxidectin against naturally acquired nematode infections of beef calves. Vet. Parasitol., 85(4): 277-288.

Williams JC, Loyacano AF, DeRosa A, Gurie J, Coombs DF, Skogerboe TL (1997). A comparison of the efficacy of two treatments of doramectin injectable, ivermectin injectable and ivermectin pour-on against naturally acquired gastrointestinal nematode infections of cattle during a winter-spring grazing season. Vet. Parasitol., 72(1): 69-77. 